Check for updates

Cite this: RSC Adv., 2018, 8, 21265

\title{
Inhibitory effects of natural organic matter on methyltriclosan photolysis kinetics $\dagger$
}

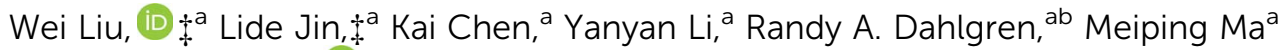 \\ and Xuedong Wang $\mathbb{D}^{*}$ *a
}

This study evaluated the effects and related mechanisms of natural organic matter (NOM) on the photolysis of methyltriclosan (MTCS), a metabolite of triclosan. Addition of two representative NOM isolates, Pony Lake fulvic acid (PLFA-microbial origin) and Suwannee River fulvic acid (SRFA-terrestrial origin), significantly inhibited the direct photolytic rate of MTCS by $\sim 70 \%$. The MTCS photolytic rate in the presence of PLFA was greater than for SRFA. NOM not only suppressed photolysis by light-shielding, but also produced ROS to oxidatively degrade MTCS and/or triplet NOM ( $\left.{ }^{3} \mathrm{NOM}^{*}\right)$ to sensitize degradation. The dual effects of light-screening and photo-sensitization led to an overall decrease in photolysis of MTCS with a positive concentration-dependence. Upon addition of NOM, EPR documented the occurrence of ${ }^{1} \mathrm{O}_{2}$ and ${ }^{\circ} \mathrm{OH}$ in the photolytic process, and the bimolecular $k$ value for the reaction of ${ }^{1} \mathrm{O}_{2}$ with MTCS was $1.86 \times 10^{6} \mathrm{M}^{-1} \mathrm{~s}^{-1}$. ROS-quenching experiments indicated that the contribution of ${ }^{\circ} \mathrm{OH}(19.1-29.5 \%)$ to indirect photolysis of MTCS was lower than for ${ }^{1} \mathrm{O}_{2}$ (38.3-58.7\%). Experiments with $\mathrm{D}_{2} \mathrm{O}$ further demonstrated that ${ }^{1} \mathrm{O}_{2}$ participated in MTCS photodegradation. Moreover, the addition of sorbic acid and $\mathrm{O}_{2}$ gas to the reaction confirmed the participation of ${ }^{3} \mathrm{NOM}^{*}$ as a key reactant in the photochemical transformation of MTCS. This is the first comprehensive analysis of NOM effects on the indirect photolysis of MTCS, which provides new insights for understanding the environmental fate of MTCS in natural environments.

Received 24th April 2018 Accepted 5th June 2018 DOI: $10.1039 / c 8 r a 03512 a$ rsc.li/rsc-advances

\section{Introduction}

Triclosan (5-chloro-2-(2,4-dichlorophenoxy)-phenol, TCS) is a common antimicrobial agent widely used in householdcleaning goods and personal care products such as shampoo, liquid soaps and toothpaste. ${ }^{1}$ Methyltriclosan (2,4-dichloro-1-(4chloro-2-methoxyphenoxy) benzene; MTCS) is a methylated product of TCS produced by several decomposition pathways. ${ }^{2}$ Due to wide-spread use, TCS and MTCS have become ubiquitous contaminants in numerous environmental and animal matrices including human body fluids.,

The degradation pathway of TCS and MTCS in natural environments includes biodegradation and photodegradation. Anaerobic and aerobic microbes can degrade TCS and MTCS, however, microbial degradation is a slow and inefficient

\footnotetext{
${ }^{a}$ Key Laboratory of Watershed Sciences and Health of Zhejiang Province, Southern Zhejiang Water Research Institute, Wenzhou Medical University, Wenzhou 325035, People's Republic of China. E-mail: zjuwxd@163.com; Fax: +86-577-8669 9122; Tel: +86-577-8668 9733

${ }^{b}$ Department of Land, Air and Water Resources, University of California, Davis, California 95616, USA

$\dagger$ Electronic supplementary information (ESI) available: Total ion chromatogram and mass spectrum of MTCS, DLLME procedure, apparent-first-order kinetic rate constants. See DOI: 10.1039/c8ra03512a

\$ These authors should be considered co-first authors.
}

process. $^{5}$ Due to their low volatility and water solubility, the photolysis of TCS and MTCS is one of the most efficient degradation pathways in aquatic environments. In recent years, considerable research has focused on mechanistic studies of TCS photolysis and demonstrated that TCS can be transformed into highly carcinogenic chemicals, such as 2,8-dichlorodibenzo- $p$-dioxin. ${ }^{6}$ Moreover, the transformation of phenolic compounds into methlyation derivatives may render its lipophilic and more bioaccumulative than the parent compound itself. $^{7,8}$ For example, it was reported that MTCS is more persistent, lipophilic, bio-accumulative and less sensitive towards photo-degradation in the environment than MTCS. ${ }^{\mathbf{9 - 1 1}}$ In spite of the recent research on TCS degradation, there is a paucity of research concerning mechanistic pathways for MTCS photolysis. Therefore, additional studies are necessary to elucidate MTCS photolysis pathways and the associated environmental risks.

This study investigated the fate of MTCS in response to irradiation with simulated sunlight and focused on the indirect photolysis induced by reactive oxygen species (ROS). Due to the ubiquitous nature of dissolved natural organic matter (NOM) in the environment, it is widely used as a photosensitizer to absorb light and subsequently generate reactive triplet state NOM $\left({ }^{3} \mathrm{NOM}^{*}\right)$ and/or induce production of ROS, such as singlet oxygen $\left({ }^{1} \mathrm{O}_{2}\right)$, superoxide anions $\left({ }^{\cdot} \mathrm{O}_{2}{ }^{-}\right)$, hydrogen peroxide 
$\left(\mathrm{H}_{2} \mathrm{O}_{2}\right)$, and hydroxyl radicals ( $\left.{ }^{\circ} \mathrm{OH}\right) .{ }^{12}$ NOM can also transfer absorbed energy to other suitable receptors thereby inducing a corresponding degradation of the receptor.

Previous studies revealed that NOM interacts with hydrophobic organic contaminants (HOCs) via a variety of mechanisms. ${ }^{13-15}$ The effect of NOM on HOC photolysis is a dual action mechanism, suppressing photolysis by light-shielding and producing ROS to oxidatively degrade HOCs or produce triplet NOM $\left({ }^{3} \mathrm{NOM}^{*}\right)$ to sensitize degradation of HOCs. ${ }^{11}$ Therefore, it is of great practical significance to study the effects of NOM on photochemical degradation of HOCs. Xu et al. (2011) reported that the photolytic rate of amoxicillin in the presence of fulvic acid was significantly increased and the photolytic contribution ratios of singlet and triplet excited state NOM was $48-74 \%{ }^{14}$ However, the contribution of NOM on photolysis of HOCs is highly dependent on the pollutant structure and concentrations. ${ }^{16}$ MTCS is a typical HOC with low water solubility, but so far the effects of NOM on the photochemical behavior of MTCS have not been rigorously examined.

Pony Lake fulvic acid (PLFA) and Suwannee River fulvic acid (SRFA) are derived from microbial and terrestrial NOM sources, respectively, and are two of the most representative NOM isolates utilized in previous studies. ${ }^{17,18}$ SRFA has lower nitrogen and sulfur functional groups and more aromatic moieties than PLFA, and thus their effects on photolysis of HOCs are likely to differ. ${ }^{19,20}$ Herein, we investigated the effects of SRFA and PLFA on the photodegradation of MTCS. A series of experiments were conducted to elucidate the ROS generation mechanism and indirect photolysis of MTCS. To the best of our knowledge, this is the first comprehensive investigation on the indirect aqueous photolysis of MTCS in the presence of PLFA and SRFA. These results enhance our understanding of the photochemical fate of MTCS and provide a theoretical basis to predict the environmental fate of other similar emerging pollutants.

\section{Materials and methods}

\subsection{Chemicals}

Methyltriclosan (MTCS) (50 $\mathrm{mg} \mathrm{L}^{-1}$ in methanol) was purchased from AccuStandard (New Haven, CT, USA). Sorbic acid (SA) and isopropyl alcohol (IPA) were obtained from Aladdin Industrial (Shanghai, China). Sodium azide $\left(\mathrm{NaN}_{3}, 99.5 \%\right)$, furfuryl alcohol (FFA, 98\%), rose Bengal (RB, 93\%), 2,2,6,6-tetramethylpiperidine (TEMP, 99\%) and 5,5-dimethyl-1-pyrroline- $\mathrm{N}$ oxide (DMPO, 97\%) were purchased from Sigma-Aldrich (Shanghai, China). Pony Lake fulvic acid (PLFA-microbial origin) and Suwannee River fulvic acid (SRFA-terrestrial origin) were acquired from the International Humic Substance Society (Denver, CO, USA) and dissolved in deionized water to form NOM isolate stock solution $\left(100 \mathrm{mg} \mathrm{L}^{-1}\right)$. Chromatographic-grade acetonitrile $\left(\mathrm{CH}_{3} \mathrm{CN}\right)$ and methanol $\left(\mathrm{CH}_{3} \mathrm{OH}\right)$ were obtained from Merck (Darmstadt, Germany). All other chemicals were of analytical grade and used as received without further purification. Deionized water $(>18 \mathrm{M} \Omega \mathrm{cm})$ was prepared using a Millipore Milli-Q system (Bedford, MA, USA).

\subsection{Analytical methods}

FFA was analyzed by high performance liquid chromatography (HPLC, 1260, Agilent, Wilmington, DE, USA) with a photodiode array detector and XDB-C18 column. MTCS was quantified by gas chromatography-mass spectrometry (Agilent GS-MS 78905977) using a HP-5MS capillary column $(30 \mathrm{~m} \times 0.32 \mathrm{~mm}$ I.D., $0.25 \mu \mathrm{m}$ film thickness, Agilent). The detailed operational parameters are available in the $\mathrm{ESI} \dagger$ section. The total ion chromatogram (TIC) and mass spectrum (MS) profile of MTCS $\left(40 \mu \mathrm{g} \mathrm{L}^{-1}\right)$ was shown in Fig S1. $\dagger$

An electron paramagnetic resonance instrument (Bruker A300 spectrometer, Bruker, Germany) was used to record electron paramagnetic resonance (EPR) signals for ${ }^{1} \mathrm{O}_{2}$ and ${ }^{\circ} \mathrm{OH}$ with trapping reagents of TEMP and DMPO, respectively.

\subsection{Photolytic experiments}

A photochemical reactor (BL-GHX-V, Shanghai, China) was used for the photolytic experiments. A $300 \mathrm{~W}$ mercury lamp with a $290 \mathrm{~nm}$ cutoff filter was used as the sunlight simulation source. The irradiance spectrum of light source was measured by a SP-300 spectroradiometer (Acton Research Corporation, USA). Fig. S2 $\uparrow$ confirmed that the $290 \mathrm{~nm}$ cutoff filters provide the transmission of wavelengths above $290 \mathrm{~nm}$. An air-cooled system was used to refrigerate the photochemical reactor.

To avoid the quenching effect of methanol on hydroxyl radicals, MTCS standard solution $\left(50 \mathrm{mg} \mathrm{L}^{-1}\right)$ was first evaporated using a gentle nitrogen flow, and then redissolved in acetonitrile to form MTCS stock solution $\left(40 \mathrm{mg} \mathrm{L}^{-1}\right)$. The MTCS stock solution was stored in the dark to avoid photochemical degradation. An appropriate volume of deionized water was added to prepare the initial concentration of $40 \mu \mathrm{g}$ $\mathrm{L}^{-1}$ MTCS $(40 \mathrm{~mL})$, which was then transferred into a quartz tube for photolytic experiments. Prior to photolysis, the quartz tube was wrapped with aluminum foil to shield the solution containing analytes from light. At given time intervals, an aliquot $(5 \mathrm{~mL})$ was transferred to a centrifuge tube for dispersive liquid-liquid microextraction (DLLME) pretreatment (Scheme S1†). In the direct photolytic experiment, NOM was not added to the photolytic solution, but it was fortified into the photolytic solution for indirect photolysis. NOM was fortified at concentrations of 5-25 mg L ${ }^{-1}$. All the experiments were carried out at least in triplicate.

\subsection{Reactive species analysis}

(1) Role of ${ }^{1} \mathrm{O}_{2}$ and $\mathrm{OH}$. The indirect photolytic mechanism was studied following addition of $\mathrm{NaN}_{3}\left(10 \mathrm{mmol} \mathrm{L}^{-1}\right.$, quencher of ${ }^{1} \mathrm{O}_{2}$ ) and IPA (100 $\mathrm{mmol} \mathrm{L}^{-1}$, quencher of $\left.{ }^{\circ} \mathrm{OH}\right)$ to the MTCS photolytic solution. ${ }^{21}$

(2) Rate constant ( $k$ value) of ${ }^{1} \mathrm{O}_{2}$ and MTCS. Under $300 \mathrm{~W}$ mercury lamp irradiation, rose bengal (RB; $2 \mu \mathrm{mol} \mathrm{L} \mathrm{L}^{-1}$, a photosensitizer for ${ }^{1} \mathrm{O}_{2}$ production) was photolyzed synchronously in solutions of MTCS and FFA $(200 \mu \mathrm{M})$. To limit direct photolysis, the MTCS solution was irradiated in a photochemical reactor equipped with a series of $420 \mathrm{~nm}$ cutoff filters. ${ }^{21} \mathrm{An}$ aliquot $(0.5 \mathrm{~mL})$ was extracted at a regular interval to determine 
FFA concentrations by HPLC. After liquid-liquid extraction using $n$-hexane as the extraction solvent, the residual MTCS concentration was determined by GC-MS.

(3) Role of ${ }^{3} \mathrm{NOM}^{*}$. The role of ${ }^{3} \mathrm{NOM}^{*}$ was investigated by addition of sorbic acid $\left(1 \mathrm{mmol} \mathrm{L}{ }^{-1}\right)$ under oxygenated or deoxygenated conditions created by purging air or $\mathrm{N}_{2}$ into the solution, respectively.

\section{Results and discussion}

\subsection{Effects of NOM on the photolytic kinetics of MTCS}

The maximum absorption spectrum of MTCS contains two bands in the ultraviolet region with absorption at $207 \mathrm{~nm}$ and $283 \mathrm{~nm}$ (Fig. S3†), respectively. The slight absorption above $290 \mathrm{~nm}$ suggested the direct absorption of simulating sunlight. Thus, the direct photolysis of MTCS using simulating sunlight $(\lambda>290 \mathrm{~nm})$ without NOM fit an apparent-first-order kinetic model (Fig. 1a). The apparent MTCS direct photolysis rate constant $(k)$ and correlation coefficient $\left(R^{2}\right)$ were $(6.81 \pm 0.20) \times$ $10^{-3} \min ^{-1}$ and 0.996 (Table $\mathrm{S} 1 \dagger$ ), respectively. Subsequently, the direct MTCS photolysis transformation efficiency in pure water was quantified as quantum yields $(\Phi)$ measured relative to a $p$-nitroanisole/pyridine actinometer. ${ }^{22}$ The calculated $\Phi$ was 0.011, revealing the nonnegligible effect of direct MTCS photolysis under simulating light. Moreover, the $k$ values for indirect photolysis were significantly decreased to $(2.71 \pm 0.12)$ $\times 10^{-3}$ and $(1.62 \pm 0.02) \times 10^{-3} \mathrm{~min}^{-1}$ in the presence of PLFA and SRFA (20 $\mathrm{mg} \mathrm{L}^{-1}$ ), respectively. These results showed that PLFA or SRFA prominently inhibited the photolysis of MTCS. Prior studies revealed that sunlight mediated organic compounds photodegradation in the presence of NOM involved direct pollutants photolysis and/or indirect contribution induced by reactive species such as hydroxyl radicals, single oxygen, triple state NOM and so on. ${ }^{23,24}$ Thus, it is necessary to
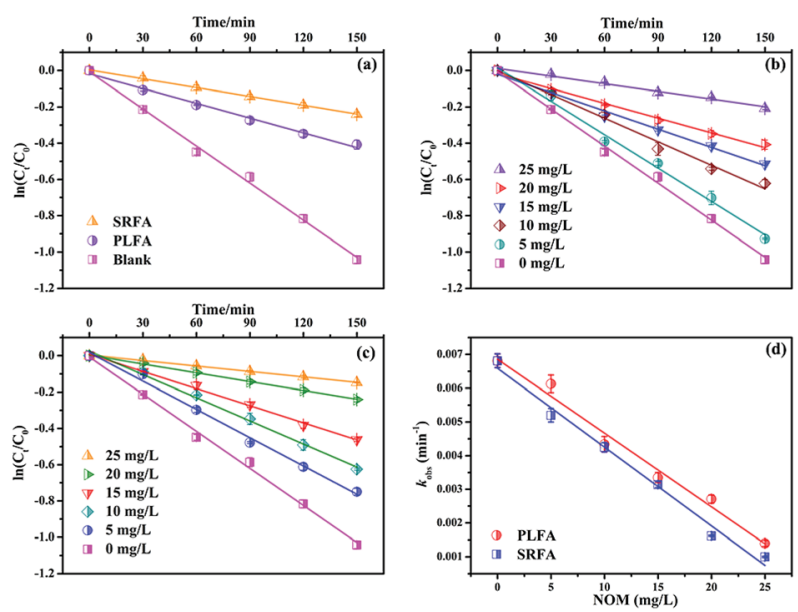

Fig. 1 (a) Photodegradation kinetics of MTCS in the absence and presence of NOM (PLFA - Pony Lake fulvic acid and SRFA is Suwannee River fulvic acid). (b) Effects of PLFA concentrations on the photodegradation kinetics of MTCS. (c) Effects of SRFA concentrations on the photodegradation kinetics of MTCS. (d) Kinetics comparison of MTCS photodegradation in the presence of PLFA and SRFA. clarify the inhibitory mechanism of PLFA and SRFA on MTCS photodegradation.

Subsequently, it further revealed that MTCS photolysis rates in the presence of SRFA $\left((1.62 \pm 0.02) \times 10^{-3} \mathrm{~min}^{-1}\right)$ was lower than PLFA $\left((2.71 \pm 0.12) \times 10^{-3} \mathrm{~min}^{-1}\right)$ (Fig. $1 \mathrm{a}$ and Table S1 $\dagger$ ). This difference originates from the contrasting chemical and optical properties of SRFA and PLFA. ${ }^{25}$ For example, Guerard et al. (2009) demonstrated that a large photo-enhancement of sulfadimethoxine (SDM) and triclocarban (TCC) occurred in the presence of PLFA, while little enhanced photolysis in the SRFA. ${ }^{17}$ The higher aromatic content in terrestrially derived NOM (SRFA) allows it to absorb more light per unit carbon resulting in a larger molar absorptivity or specific UV absorbance compared to autochthonous NOM (PLFA). ${ }^{26}$ Moreover, Felcyn et al. (2012) found that NOM from microbial origin (PLAF) was an excellent photosensitizer compared to NOM from terrestrial sources (SRFA). ${ }^{18}$

Photodegradation rates for MTCS were significantly decreased from $(6.81 \pm 0.20) \times 10^{-3} \mathrm{~min}^{-1}$ to $(1.40 \pm 0.09) \times$ $10^{-3}$ or $(1.00 \pm 0.02) \times 10^{-3} \mathrm{~min}^{-1}$ (Table S2†) with increasing NOM concentrations from 0 to $25 \mathrm{mg} \mathrm{L}^{-1}$ (Fig. $1 \mathrm{~b}$ and c). However, MTCS photodegradation efficiency was slightly higher in the presence of PLFA compared to SRFA (Fig. 1d). Because the photolysis of organic contaminants in sunlight-induced natural waters is caused by NOM-derived active substances (e.g., ${ }^{1} \mathrm{O}_{2}$, ${ }^{\circ} \mathrm{OH}$ and $\left.{ }^{3} \mathrm{NOM}^{*}\right)$, NOM with differing chemical compositions can lead to different indirect reactions and rates.

\subsection{Effects of ROS on MTCS indirect photodegradation}

A series of quencher experiments were then carried out to qualitatively describe the effects of ${ }^{1} \mathrm{O}_{2}$ and ${ }^{\circ} \mathrm{OH}$ in the indirect photolysis process. MTCS solutions containing $20 \mathrm{mg} \mathrm{L}^{-1}$ NOM were investigated in pure water under irradiation $(\lambda>$ $290 \mathrm{~nm}$ ), with the addition of IPA as a ${ }^{\circ} \mathrm{OH}$ scavenger and $\mathrm{NaN}_{3}$ as a ${ }^{1} \mathrm{O}_{2}$ scavenger (Fig. 2). ${ }^{21}$ The MTCS photolytic rate in the presence of PLFA decreased from $(2.71 \pm 0.12) \times 10^{-3}$ to $(1.91$ $\pm 0.06) \times 10^{-3} \mathrm{~min}^{-1}$ with the addition of IPA revealing the specific contribution of ${ }^{\circ} \mathrm{OH}$ to MTCS photodegradation in the presence of PLFA. Further, the $k$ value prominently decreased from $(2.71 \pm 0.12) \times 10^{-3}$ to $(1.12 \pm 0.05) \times 10^{-3} \mathrm{~min}^{-1}$ in the presence of $\mathrm{NaN}_{3}$, which demonstrated that ${ }^{1} \mathrm{O}_{2}$ played a crucial role in the indirect photolysis of MTCS. Similarly, MTCS photodegradation constants in the presence of SRFA
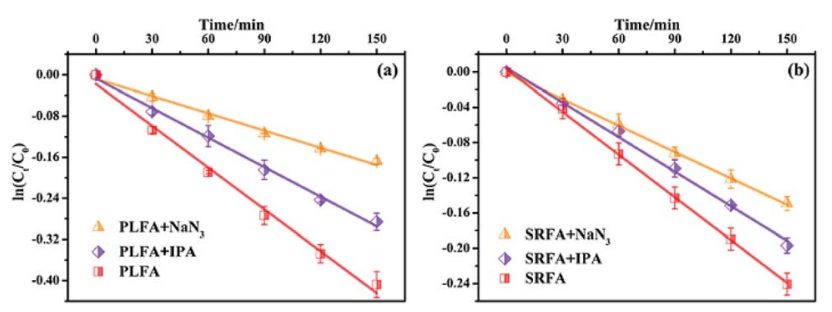

Fig. 2 Effects of $\mathrm{NaN}_{3}$ and isopropyl alcohol (IPA) on photodegradation kinetics of MTCS in the presence of (a) PLFA (Pony Lake fulvic acid, $20 \mathrm{mg} \mathrm{L}^{-1}$ ) and (b) SRFA (Suwannee River fulvic acid, $20 \mathrm{mg} \mathrm{L}^{-1}$ ). 
decreased from $(1.62 \pm 0.02) \times 10^{-3}$ to $(1.31 \pm 0.04) \times 10^{-3}$ and $(1.00 \pm 0.01) \times 10^{-3} \mathrm{~min}^{-1}$ with the addition of IPA and $\mathrm{NaN}_{3}$ (Table 1), respectively. The contribution of ${ }^{\circ} \mathrm{OH}$ and ${ }^{1} \mathrm{O}_{2}$ to the MTCS photolysis process $\left(R^{\cdot}{ }_{\mathrm{OH}}\right.$ and $\left.R^{1} \mathrm{O}_{2}\right)$ were calculated as follows:

$$
\begin{gathered}
R \cdot O H=\frac{k \cdot O H(P W)}{k_{\mathrm{PW}}}=\frac{k_{\mathrm{PW}}-k_{\mathrm{PW}+\mathrm{IPA}}}{k_{\mathrm{PW}}} \\
R_{\mathrm{O}_{2}}=\frac{k_{\mathrm{O}_{2}(P W)}}{k_{\mathrm{PW}}}=\frac{k_{\mathrm{PW}}-k_{\left(\mathrm{PW}+\mathrm{NaN}_{3}\right)}}{k_{\mathrm{PW}}}
\end{gathered}
$$

where $k_{\mathrm{PW}}, k_{\mathrm{PW}+\mathrm{IPA}}$ and $k_{\mathrm{PW}+\mathrm{NaN}_{3}}$ are the photodegradation rate constants of MTCS without quencher and in the presence of IPA and $\mathrm{NaN}_{3}$, respectively. The $k^{1} \mathrm{O}_{2}(\mathrm{PW})$ and $k^{\cdot} \mathrm{OH}(\mathrm{PW})$ terms are the MTCS photodegradation rate constants induce by ${ }^{1} \mathrm{O}_{2}$ and ${ }^{\circ} \mathrm{OH}$, respectively. ${ }^{27,28}$ Table 1 summarizes the photodegradation rate constants $(k)$ for MTCS under different conditions. The contribution ratios of ${ }^{1} \mathrm{O}_{2}$ and ${ }^{\circ} \mathrm{OH}$ to MTCS photodegradation in the presence of PLFA were $58.7 \%$ and $29.5 \%$, respectively. The corresponding contribution ratios for ${ }^{1} \mathrm{O}_{2}$ and ${ }^{\circ} \mathrm{OH}$ in the presence of SRFA were $38.3 \%$ and $19.1 \%$, respectively. These results confirmed that both ${ }^{1} \mathrm{O}_{2}$ and ${ }^{\circ} \mathrm{OH}$ play crucial roles in the indirect photodegradation of MTCS in the presence of PLFA and SRFA. The contribution ratio from ${ }^{\circ} \mathrm{OH}(19.1-29.5 \%)$ in the indirect photolysis of MTCS was smaller than that of ${ }^{1} \mathrm{O}_{2}(38.3-$ $58.7 \%)$.

To clarify the dual contribution of light-shielding and ROS on the MTCS photolysis, light screening factors $(S)$ was calculated during the photolysis process in the presence of PLFA and MTCS. $^{29}$ The results revealed that $S$ of SRFA and PLFA for the MTCS photolysis were 0.101 and 0.047 , respectively, suggesting the higher contribution of light-shielding on MTCS photolysis. Thus, we concluded that the overall decrease in MTCS photolysis was caused by the inhibitive effect of light-shielding and promoted effect of ROS in the presence of PLFA and SRFA.

Subsequently, the steady-state concentration of ${ }^{\circ} \mathrm{OH}$ was determined by monitoring the generation of 2-hydroxyterephthalic acid (hTPA) using terephthalate (TPA) as a probe. ${ }^{30}$ Fig. S4† shown that the hTPA concentrations increased by prolonging the photolysis time in the presence of SRFA and PLFA. The calculated steady state concentrations of ${ }^{\circ} \mathrm{OH}$ were $1.73 \times 10^{-16}$ and $1.33 \times 10^{-16} \mathrm{M}$ for the SRFA and PLFA, respectively. However, limited hTPA were detected in the photolysis systems with the addition of IPA. All of these results

Table 1 Photolytic rate constants for MTCS under UV-Vis irradiation ( $\lambda$ $>290 \mathrm{~nm})^{a}$

\begin{tabular}{lll}
\hline$k$ & $\mathrm{SRFA}^{*}\left(\times 10^{-3} \mathrm{~min}^{-1}\right)$ & $\mathrm{PLFA}^{*}\left(\times 10^{-3} \mathrm{~min}^{-1}\right)$ \\
\hline$k_{\mathrm{PW}}$ & $1.62 \pm 0.02$ & $2.71 \pm 0.12$ \\
$k_{\mathrm{PW}+\mathrm{IPA}}$ & $1.31 \pm 0.04$ & $1.91 \pm 0.06$ \\
$k \cdot \mathrm{OH}(\mathrm{PW})$ & 0.31 & 0.80 \\
$k_{\mathrm{PW}+\mathrm{NaN}}$ & $1.00 \pm 0.01$ & $1.12 \pm 0.05$ \\
$k^{1} \mathrm{O}_{2}(\mathrm{PW})$ & 0.62 & 1.59
\end{tabular}

$a *$ PLFA is Pony Lake fulvic acid (microbial origin, $20 \mathrm{mg} \mathrm{L}^{-1}$ ) and SRFA is Suwannee River fulvic acid (terrestrial origin, $20 \mathrm{mg} \mathrm{L}^{-1}$ ). confirmed the important of reactive oxygen species on the MTCS indirect photolysis.

\subsection{EPR detection of ${ }^{\cdot} \mathrm{OH}$ and ${ }^{1} \mathrm{O}_{2}$}

EPR was used to identify ROS formation during the MTCS photodegradation process. ${ }^{31-34}$ TEMP is a typical capture agent for ${ }^{1} \mathrm{O}_{2}$, which reacts with ${ }^{1} \mathrm{O}_{2}$ to produce a stable paramagnetic adduct TEMP- ${ }^{1} \mathrm{O}_{2}$ with a characteristic line of $1: 1: 1 .^{31}$ Typical $1: 1: 1$ triplet signals were obtained after irradiation of MTCS, TEMP and NOM (Fig. 3a and c) revealing generation of ${ }^{1} \mathrm{O}_{2}$ during the photolysis process. Moreover, the signal intensity increased significantly with prolonged irradiation time. To confirm the contribution of ${ }^{1} \mathrm{O}_{2}$ on the formation of TEMP- ${ }^{1} \mathrm{O}_{2}, \mathrm{NaN}_{3}$ was added to the MTCS, NOM and TEMP mixture to inhibit ${ }^{1} \mathrm{O}_{2}$. The $\mathrm{NaN}_{3}$ strongly decreased the triplet signal for TEMP- $^{1} \mathrm{O}_{2}$ (Fig. 3), which verified that formation of the TEMP- ${ }^{1} \mathrm{O}_{2}$ spin adduct was inhibited. For comparison, the EPR signal of TEMP- ${ }^{1} \mathrm{O}_{2}$ was also collected during the photolysis process without NOM. Fig. S5a $†$ revealed that limited TEMP- ${ }^{1} \mathrm{O}_{2}$ signal was obtained in the absence of NOM. In total, these results confirmed that ${ }^{1} \mathrm{O}_{2}$ was generated during MTCS photolysis in the presence of PLFA and SRFA.

DMPO is a typical capture agent for ${ }^{\circ} \mathrm{OH}$, which reacts with ${ }^{\circ} \mathrm{OH}$ to produce DMPO- $\mathrm{OH}$, a stable paramagnetic adduct with a characteristic line of $1: 2: 2: 1 .^{35}$ Four characteristic peaks with a $1: 2: 2: 1$ quarter pattern were obtained after irradiation of MTCS and NOM, indicating generation of ${ }^{\circ} \mathrm{OH}$ (Fig. 4). The signal intensity for DMPO- ${ }^{\circ} \mathrm{OH}$ increased significantly with increased irradiation time (Fig. 4a and c). The signal sharply decreased with IPA addition under identical conditions (Fig. 4b and d), confirming that the EPR signal was formed by reaction of DMPO and ${ }^{\circ} \mathrm{OH}$. Moreover, no DMPO${ }^{\circ} \mathrm{OH}$ signal was obtained in the absence of NOM during the
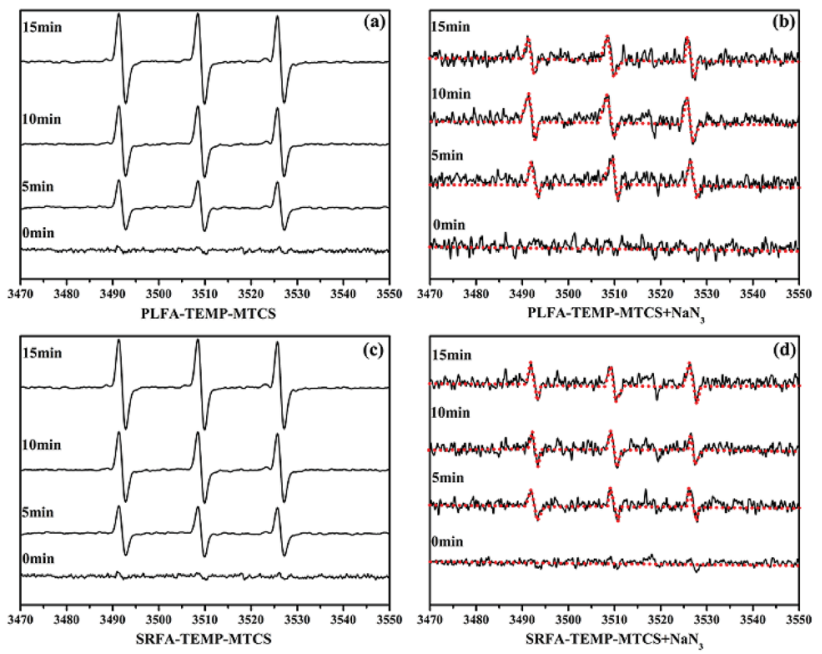

Fig. 3 EPR spectra of ${ }^{1} \mathrm{O}_{2}$ spin-trapping with TEMP under different conditions. (a) PLFA (20 mg L $\left.{ }^{-1}\right)$, (b) PLFA $\left(20 \mathrm{mg} \mathrm{L}^{-1}\right) / \mathrm{NaN}_{3}$, (c) SRFA (20 mg L ${ }^{-1}$ ), (d) SRFA (20 mg L $\left.{ }^{-1}\right) / \mathrm{NaN}_{3}$. PLFA is Pony Lake fulvic acid and SRFA is Suwannee River fulvic acid. 

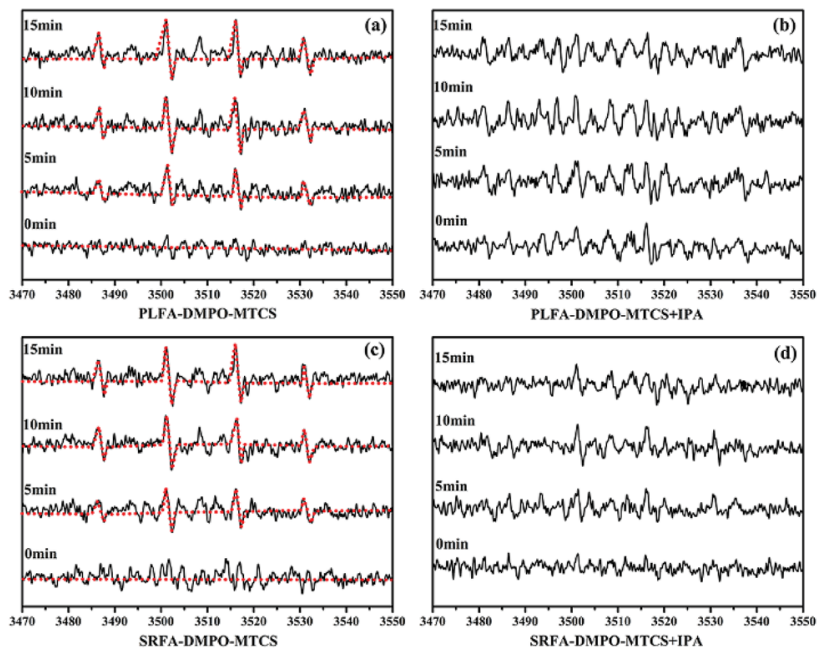

Fig. 4 EPR spectra of ${ }^{\circ} \mathrm{OH}$ spin-trapping with DMPO under different conditions. (a) PLFA (20 mg L-1), (b) PLFA (20 mg L $\left.\mathrm{mg}^{-1}\right) /$ IPA, (c) SRFA $\left(20 \mathrm{mg} \mathrm{L}^{-1}\right)$, (d) SRFA (20 mg L $\left.{ }^{-1}\right) /$ IPA. PLFA is Pony Lake fulvic acid and SRFA is Suwannee River fulvic acid.

MTCS photolysis process (Fig $\left.S 5 b^{\dagger}\right)^{\circ}$. In sum, the EPR results demonstrated the generation of ${ }^{\circ} \mathrm{OH}$ and ${ }^{1} \mathrm{O}_{2}$ during MTCS photolysis in the presence of NOM.

\subsection{Kinetic studies for ${ }^{1} \mathrm{O}_{2}$ reaction with MTCS}

To evaluate the bimolecular reaction rate constant of ${ }^{1} \mathrm{O}_{2}$ with MTCS at pH 7.0, rose bengal (RB) and FFA were used as photosensitizer and reference compounds in the MTCS photodegradation system, respectively. ${ }^{36}$ From the steady-state ${ }^{1} \mathrm{O}_{2}$ concentration and reaction rate constant, it is possible to determine the ${ }^{1} \mathrm{O}_{2}$ contribution to the photolytic process. Concentrations of the target (MTCS) and reference (FFA) compounds were simultaneously monitored to evaluate their reaction kinetics with ${ }^{1} \mathrm{O}_{2}$. The bimolecular reaction rate constant of FFA with ${ }^{1} \mathrm{O}_{2}\left(k_{\mathrm{FFA}}\right)$ was determined to be $1.20 \times 10^{8}$ $\mathrm{M}^{-1} \mathrm{~s}^{-1}$ and was used in calculating the bimolecular reaction rate constant for MTCS with ${ }^{1} \mathrm{O}_{2}\left(k^{1} \mathrm{O}_{2}\right)$ via eqn (3):

$$
\ln \frac{[S]_{\mathrm{t}}}{[S]_{0}}=\frac{k_{1} \mathrm{O}_{2}, S}{k^{1} \mathrm{O}_{2}, \mathrm{FFA}} \ln \frac{[\mathrm{FFA}]_{\mathrm{t}}}{[\mathrm{FFA}]_{0}}
$$

where $k^{1} \mathrm{O}_{2}$, FFA is the rate constant of FFA with ${ }^{1} \mathrm{O}_{2}$, and $k^{k_{1}} \mathrm{O}_{2}, S$ is the rate constant of MTCS with ${ }^{1} \mathrm{O}_{2} \cdot{ }^{10,37-39}$ The bimolecular reaction rate constant for the reaction of ${ }^{1} \mathrm{O}_{2}$ with MTCS was $1.86 \times 10^{6} \mathrm{M}^{-1} \mathrm{~s}^{-1}$ (Fig. 5a), which was slightly lower than those for other organic contaminants. For example, Barbieri et al. (2008) reported that the $k$ value for the reaction between bisphenol A and ${ }^{1} \mathrm{O}_{2}$ was $1.01 \times 10^{8} \mathrm{M}^{-1} \mathrm{~s}^{-1}$ in pure water $(\mathrm{pH}=$ $10),{ }^{40}$ which was nearly two orders of magnitude higher than for ${ }^{1} \mathrm{O}_{2}$ with MTCS. Xie et al. (2013) confirmed that the direct photolytic rate and secondary reaction rate of anions with ${ }^{1} \mathrm{O}_{2}$ was much higher than those of neutral molecules. ${ }^{41}$ Thus, we concluded that ${ }^{1} \mathrm{O}_{2}$ involved into the MTCS photodegradation and its rate constant dependent on the organic pollution molecular structure.

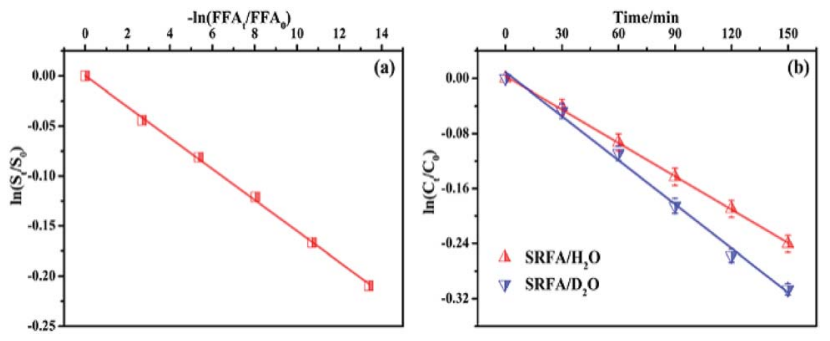

Fig. 5 (a) Loss of MTCS versus loss of furfuryl alcohol (FFA) in the presence of rose bengal. (b) Effect of $\mathrm{D}_{2} \mathrm{O}$ on the photodegradation of MTCS in aqueous solution. SRFA (20 $\mathrm{mg} \mathrm{L}^{-1}$ ) is Suwannee River fulvic acid.

\subsection{Photolysis of MTCS in $\mathrm{D}_{2} \mathrm{O}$ solution}

Due to the longer lifetime of ${ }^{1} \mathrm{O}_{2}$ in deuterated solvents, $\mathrm{D}_{2} \mathrm{O}$ was used as the MTCS solvent to further examine the role of ${ }^{1} \mathrm{O}_{2}$ in the photolytic process. Literature sources report that the reaction rate in $\mathrm{D}_{2} \mathrm{O}$ should be about 14 times higher than in $\mathrm{H}_{2} \mathrm{O}$, if the degradation was fully controlled by ${ }^{1} \mathrm{O}_{2} \cdot{ }^{42}$ Thus, the rate constant in $\mathrm{D}_{2} \mathrm{O}$ should be significantly increased compared to $\mathrm{H}_{2} \mathrm{O}$ under the premise that the reaction with ${ }^{1} \mathrm{O}_{2}$ was the primary transformation pathway for MTCS degradation. ${ }^{43}$ However, the measured degradation rates for MTCS in $\mathrm{D}_{2} \mathrm{O}\left((2.13 \pm 0.08) \times 10^{-3} \mathrm{~min}^{-1}\right)$ did not show a significant increase over that in $\mathrm{H}_{2} \mathrm{O}\left((1.62 \pm 0.02) \times 10^{-3} \mathrm{~min}^{-1}\right)$ (Fig. 5b). This indicates that indirect photolysis related to ${ }^{1} \mathrm{O}_{2}$ was not the exclusive mechanism responsible for photodegradation of MTCS. Therefore, we concluded that MTCS photodegradation in the presence of NOM could be ascribed to synergistic effects among ${ }^{1} \mathrm{O}_{2},{ }^{\circ} \mathrm{OH}$ and direct photolysis.

\subsection{Role of ${ }^{3}$ NOM*}

As an effective photosensitizer, NOM can absorb sunlight to form excited states (e.g., $\left.{ }^{3} \mathrm{NOM}^{*}\right)$. The ${ }^{3} \mathrm{NOM}^{*}$ can then react with dissolved oxygen to generate a series of ROS, such as ${ }^{1} \mathrm{O}_{2}$, $\mathrm{O}_{2}{ }^{-}$, and ${ }^{\circ} \mathrm{OH}$. Organic molecules can subsequently be degraded by these ROS or react by transferring electrons or energy with ${ }^{3} \mathrm{NOM}^{*}$. Thus, it is necessary to distinguish the effect of ${ }^{3} \mathrm{NOM}^{*}$ on MTCS photodegradation in the presence of NOM. Oxygen can be used as a triplet-excited-state quencher to inhibit the contribution of ${ }^{3} \mathrm{NOM}^{*} \cdot{ }^{15,44}$ Hence, MTCS photodegradation was conducted with $\mathrm{O}_{2}$ (air-saturated) and without $\mathrm{O}_{2}\left(\mathrm{~N}_{2}\right.$-saturated) to evaluate the contribution of ${ }^{3} \mathrm{NOM}^{*}$ (Fig. $6 \mathrm{a}$ and Table $\mathrm{S} 3 \dagger)$. Photodegradation rates for MTCS in $\mathrm{N}_{2}$-saturated conditions $\left((3.44 \pm 0.03) \times 10^{-3} \mathrm{~min}^{-1}\right.$ and $(4.12 \pm 0.11)$ $\left.\times 10^{-3} \mathrm{~min}^{-1}\right)$ were significantly higher than for air-saturated conditions $\left((1.62 \pm 0.02) \times 10^{-3} \mathrm{~min}^{-1}\right.$ and $(2.71 \pm 0.12) \times$ $10^{-3} \mathrm{~min}^{-1}$ ) in the presence of SRFA and PLFA, respectively. These results indicate that the direct reaction of MTCS with ${ }^{3} \mathrm{NOM}^{*}$ was important in the absence of oxygen.

To confirm the involvement of ${ }^{3} \mathrm{NOM}^{*}$ in aerobic MTCS photolysis, the effect of a triplet quencher (sorbic acid) on MTCS indirect photolytic rates was evaluated. ${ }^{45}$ It revealed that MTCS photodegradation rates in the presence of SRFA and PLFA were significantly decreased from $(1.62 \pm 0.02) \times 10^{-3}$ and $(2.71 \pm$ 

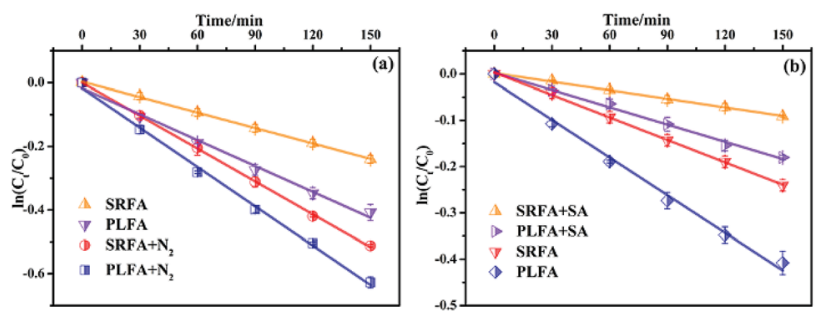

Fig. 6 (a) MTCS photodegradation in the presence of PLFA $\left(20 \mathrm{mg} \mathrm{L}^{-1}\right.$ ) and SRFA (20 $\mathrm{mg} \mathrm{L}^{-1}$ ) under nitrogen (anaerobic) and air saturated (aerobic) conditions. (b) Effect of added triplet quencher sorbic acid (SA) on the photodegradation of MTCS in the presence of PLFA (20 $\mathrm{mg} \mathrm{L}^{-1}$ ) and SRFA (20 mg L ${ }^{-1}$ ). PLFA is Pony Lake fulvic acid and SRFA is Suwannee River fulvic acid.

$0.12) \times 10^{-3} \mathrm{~min}^{-1}$ to $(0.61 \pm 0.01) \times 10^{-3}$ and $(1.24 \pm 0.05) \times$ $10^{-3} \min ^{-1}$ when sorbic acid was added to quench ${ }^{3} \mathrm{NOM}^{*}$ (Fig. 6b and Table S3 $\dagger$ ), inferring that ${ }^{3} \mathrm{NOM}^{*}$ plays an important role in the indirect photolysis of MTCS. However, it must be noted that sorbic acid not only quenches ${ }^{3} \mathrm{NOM}^{*}$, but also ${ }^{1} \mathrm{O}_{2}$, and thus it can simultaneously reduce the steady-state concentrations of both ${ }^{3} \mathrm{NOM}^{*}$ and ${ }^{1} \mathrm{O}_{2}$ in aqueous solutions. Thus, decreased indirect reaction rates for MTCS may result from a decrease in ${ }^{3} \mathrm{NOM}^{*}$ and/or ${ }^{1} \mathrm{O}_{2}$. Consequently, the photodegradation efficiency of MTCS was strongly inhibited by addition of sorbic acid. Overall, these findings support that the indirect photolysis of MTCS in the presence of NOM was mainly due to reaction with ${ }^{1} \mathrm{O}_{2}$ induced by the activation of ${ }^{3} \mathrm{NOM}^{*}$, whereas the contribution of ${ }^{\circ} \mathrm{OH}$ and direct photodegradation was less important.

\section{Conclusions}

In this study, the photodegradation of MTCS in the presence of PLFA (microbial origin) or SRFA (terrestrial origin) were systematically investigated. Results confirmed that both PLFA and SRFA significantly inhibited direct MTCS photodegradation via light-shielding. Further, the indirect photodegradation of MTCS was depressed by reaction between ${ }^{3} \mathrm{NOM}^{*}$ and $\mathrm{O}_{2}$ to generate ROS rather than the direct reaction between ${ }^{3} \mathrm{NOM}^{*}$ and MTCS. The results of this study provide new insights on the indirect photolysis of MTCS in the presence of NOM under simulated natural environmental conditions.

\section{Conflicts of interest}

There are no conflicts to declare.

\section{Acknowledgements}

This work was jointly supported by the National Natural Science Foundation of China (Grants 21577107 and 21707105), Zhejiang Provincial Natural Science Foundation (Grant LY15B070009), Zhejiang Provincial Public Benefit Project (Grants 2016C34011 and LGF18B070004), Wenzhou City Water Pollution Control and Governance Technology Innovation Project (Grants W20170001 and W20170017), Research and Development Fund of Wenzhou Medical University (Grant QTJ16013), and Zhejiang Provincial Xinmiao Talent Project (Grant 2016R413021).

\section{Notes and references}

1 L. M. Mcmurry, M. Oethinger and S. B. Levy, Nature, 1998, 394, 531-532.

2 P. Canosa, I. Rodríguez, E. Rubí, M. Ramil and R. Cela, J. Chromatogr. A, 2008, 1188, 132-139.

3 A. M. Calafat, X. Ye, L. Y. Wong, J. A. Reidy and L. L. Needham, Environ. Health Perspect., 2008, 116, 303-307. 4 J. Parkkonen, Chemosphere, 2002, 46, 1485-1489.

5 A. Lindström, I. J. Buerge, T. Poiger, P. A. Bergqvist, M. D. Müller and H. R. Buser, Environ. Sci. Technol., 2002, 36, 2322-2329.

6 M. Mezcua, M. J. Gómez, I. Ferrer, A. Aguera, M. D. Hernando and A. R. Fernández-Alba, Anal. Chim. Acta, 2004, 524, 241-247.

7 R. Valo and M. Salkinoja-Salonen, J. Gen. Appl. Microbiol., 1986, 32, 505-517.

8 M. M. Häggblom, D. Janke, P. J. M. Middeldorp and M. S. Salkinoja-Salonen, Arch. Microbiol., 1989, 152, 6-9.

9 M. E. Balmer, T. Poiger, C. Droz, K. Romanin, P. A. Bergqvist, M. D. Müller and H. R. Buser, Environ. Sci. Technol., 2004, 38, 390-395.

10 A. Lindström, I. J. Buerge, T. Poiger, P. A. Bergqvist, M. D. Müller and H. R. Buser, Environ. Sci. Technol., 2002, 36, 2322-2329.

11 H. Wang, J. Gao, N. Yu, J. Qu, F. Fang, H. Wang, M. Wang and X. Wang, Talanta, 2016, 154, 381-391.

12 O. N. Aleksandrova, M. Schulz and M. Matthies, Water, Air, Soil Pollut., 2011, 221, 203-214.

13 C. Yong, C. Hu, X. X. Hu and J. H. Qu, Environ. Sci. Technol., 2009, 43, 2760-2765.

14 H. Xu, W. J. Cooper, J. Jung and W. Song, Water Res., 2011, 45, 632-638.

15 W. Yang, S. Ben Abdelmelek, Z. Zheng, T. An, D. Zhang and W. Song, Water Res., 2013, 47, 6558-6565.

16 S. Canonica and H. U. Laubscher, Photochem. Photobiol. Sci., 2008, 7, 547-551.

17 J. J. Guerard, P. L. Miller, T. D. Trouts and Y. P. Chin, Aquat. Sci., 2009, 71, 160-169.

18 J. R. Felcyn, J. C. Davis, L. H. Tran, J. C. Berude and D. E. Latch, Environ. Sci. Technol., 2012, 46, 6698-6704.

19 J. Chen, B. Gu, E. J. Leboeuf, H. Pan and S. Dai, Chemosphere, 2002, 48, 59-68.

20 C. Jiang, G. R. Aiken and H. Hsu-Kim, Environ. Sci. Technol., 2015, 49, 11476-11484.

21 D. E. Latch, B. L. Stender, J. L. Packer, W. A. Arnold and K. Mcneill, Environ. Sci. Technol., 2003, 37, 3342-3350.

22 M. Wang, H. l. Wang, R. B. Zhang, M. P. Ma, K. Mei, F. Fang and X. D. Wang, PLoS One, 2015, 10, e0135400.

23 S. S. Walse, S. L. Morgan, L. Kong and J. L. Ferry, Environ. Sci. Technol., 2004, 38, 3908-3915.

24 W. Chu, K. H. Chan, C. Y. Kwan and C. T. Jafvert, Environ. Sci. Technol., 2005, 39, 9211-9216. 
25 J. Wenk, M. Aeschbacher, M. Sander, U. von Gunten and S. Canonica, Environ. Sci. Technol., 2015, 49, 8541-8549.

26 Y. P. Chin, G. Aiken and E. O'Loughlin, Environ. Sci. Technol., 1994, 28, 1853-1858.

27 L. K. Ge, J. W. Chen, X. L. Qiao, L. Jing and X. Y. Cai, Environ. Sci. Technol., 2009, 43, 3101-3107.

28 R. G. Zepp, P. F. Schlotzhauer and R. M. Sink, Environ. Sci. Technol., 1985, 19, 74-81.

29 S. S. Walse, S. L. Morgan, L. Kong and J. L. Ferry, Environ. Sci. Technol., 2004, 38, 3908-3915.

30 T. Zeng and W. A. Arnold, Environ. Sci. Technol., 2013, 47, 6735-6745.

31 M. Zhan, X. Yang, Q. Xian and L. Kong, Chemosphere, 2006, 63, 378-386.

32 Y. Chen, C. Hu, J. Qu and M. Yang, J. Photochem. Photobiol., A, 2008, 197, 81-87.

33 X. D. Zhu, Y. J. Wang, C. Liu, W. X. Qin and D. M. Zhou, Chemosphere, 2014, 107, 274-281.

34 Y. Yao, Y. Mao, Q. Huang, L. Wang, Z. Huang, W. Lu and W. Chen, J. Hazard. Mater., 2014, 264, 323-331.
35 L. Khachatryan, C. A. McFerrin, R. W. Hall and B. Dellinger, Environ. Sci. Technol., 2014, 48, 9220-9226.

36 F. E. Scully and J. Hoigné, Chemosphere, 1987, 16, 681-694. 37 S. Halladja, A. T. H. J. Aguer, A. A. Boulkamh and C. Richard, Environ. Sci. Technol., 2007, 41, 6066-6073.

38 M. M. Kelly and W. A. Arnold, Environ. Sci. Technol., 2012, 46, 5396-5403.

39 A. L. Boreen, B. L. Edhlund, J. B. Cotner and K. Mcneill, Environ. Sci. Technol., 2008, 42, 5492-5498.

40 Y. Barbieri, W. A. Massad, D. J. Diaz, J. Sanz, F. Amat-Guerri and N. A. Garcia, Chemosphere, 2008, 73, 564-571.

41 Q. Xie, J. Chen, H. Zhao, X. Qiao, X. Cai and X. Li, Chemosphere, 2013, 90, 188-194.

42 P. B. Merkel and D. R. Kearns, J. Am. Chem. Soc., 1972, 94, 7244-7253.

43 I. B. C. Matheson, J. Lee and A. D. King, Chem. Phys. Lett., 1978, 55, 49-51.

44 Y. Li, Y. Pan, L. Lian, S. Yan, W. Song and X. Yang, Water Res., 2017, 109, 266-273.

45 J. E. Grebel, J. J. Pignatello and W. A. Mitch, Water Res., 2011, 45, 6535-6544. 